\title{
Monitoring Noise Pollution in Urban Area Through SUNET System
}

\author{
Mihai ILIESCU $^{1 *}$, Rodica CADAR ${ }^{1}$, Mirela BECA ${ }^{1}$ \\ 1) Faculty of Civil Engineering, Technical University of Cluj-Napoca, \\ Department of Infrastructure, C-tin Daicoviciu Street, no.15, Cluj-Napoca, Romania \\ * corresponding author: mihai.iliescu@infra.utcluj.ro
}

Bulletin USAMV series Agriculture 72(1)/2015

Print ISSN 1843-5246; Electronic ISSN 1843-5386

DOI 10.15835/buasvmcn-agr: 11155

\begin{abstract}
Modelling the sound pressure levels of traffic noise at any location in an urban area requires a series of steps in order to collect, collat and report data, in accordance with the European Community legislation (Directive 2002/49/EC of the European Parliament and of the Council of 25 June 2002). The present paper presents a model performed through SUNET (System for Urban Noise and Eco-Traffic) system, including data collection equipment (Sound Metter Level UC2010-2, Weather Station (Tehno Line WS 550), software to process them (SoundPLAN) and harmonised indicators $\left(\mathrm{L}_{\text {den }}\right.$ and $\mathrm{L}_{\text {night }}-\mathrm{A}$-weighted long-term average sound level as defined in ISO 1996-2: 1987) in order to validate the results. The study refers to a major road section in agglomeration Cluj-Napoca and considers all aspects regarding the urban area (type of road, architecture, buildings etc.) and traffic (speed, traffic composition, traffic density flow etc.). Measurements made in major roads in Cluj-Napoca reveal overcoming of limit values for almost all intervals of day. Even if for the road network from Cluj-Napoca, many actions were taken, like lower speed limits, heavy traffic prohibited, improved surface course, the maximum values allowed for 2012 are exceeded and more actions are needed in order to achieve these targets. Monitoring noise levels on the urban road network through the equipment and methods according to the law leads to actual results and an appropriate implementation of action plans.
\end{abstract}

Keywords: environment, noise, traffic.

\section{INTRODUCTION}

In the Green Paper on Future Noise Policy, the European Commission addressed noise in the environment as one of the main environmental problems in Europe. According to the World Health Organization in Europe, road traffic noise is "second environmental factor favoring the urban disease" after air pollution. In the European Union about $40 \%$ of the population is exposed to a sound pressure level exceeding $55 \mathrm{~dB}(\mathrm{~A})$ and $20 \%$ at levels exceeding $65 \mathrm{~dB}(\mathrm{~A})$ with the source traffic. (SILENCE, 2008)

Directive 2002/49 / EC of the European Parliament and of the Council of 25 June 2002 should provide a basis for developing Community measures to reduce noise emitted by the major sources, in particular road and rail vehicles and infrastructure, and the development of additional measures in the short, medium and long term. The purpose of this Directive is to establish a 
Tab. 1. Maximum values allowed $\left(\mathrm{L}_{\mathrm{den}}\right.$ and $\left.\mathrm{L}_{\text {night }}\right)$ for noise in Romania (H.G. 321, 2005)

\begin{tabular}{ccccc}
\hline & $\mathrm{L}_{\mathrm{den}}-\mathrm{dB}(\mathrm{A})$ & \multicolumn{2}{c}{$\mathrm{L}_{\text {night }}-\mathrm{dB}(\mathrm{A})$} \\
\hline Noise source & Target for 2012 & Maximum allowed & Target for 2012 & Maximum allowed \\
\hline Roads & 65 & 70 & 50 & 60 \\
\hline
\end{tabular}

common approach to avoid, prevent or reduce on a prioritized basis the harmful effects, including annoyance, due to ambient noise and create a basis for managing urban noise through:

- monitoring of environmental issues by requiring competent authorities of the Member States undertake strategic noise maps for major roads, major railways, major airports and agglomerations, industrial areas and ports using harmonized noise indicators such as Lden and Lnight ;

- informing and consulting the public about noise exposure of the population and its effects, but also about the measures can be taken to limit noise pollution;

- launch of local issues by requiring local authorities on the assessment and management of environmental noise, to manage environmental noise and its effects, taking into account the strategic noise maps. (END, 2002)

Directive does not set limits on noise indicators or measures to be taken by action plans. Threshold limit values and measures that can be taken in the action plans are established by each Member State individually.

In line with the EU rules, the Romanian Government Decision 321/2005 adopted in 2005 on the assessment and management of environmental noise, addressing national methodology to avoid, prevent or reduce harmful effects caused by ambient noise including annoyance and also sets maximum values allowed for noise level indicators $\mathrm{L}_{\text {den }}$ and $\mathrm{L}_{\text {night }}$ in our country (Tab. 1).

The main source in urban area of noise pollution is transportation systems especially motor vehicle and it has become a serious impediment to the quality of life and even the health of urban populations (Sandberg et al, 2002).

Like any other noise sources, those caused by transport spectra are characterized by noise, sound pressure levels and also by variation of this levels over time. The sources of urban noise caused by transport are particularly low frequency nature and partly medium frequency (Manvell, 1999). Urban noise caused by transport depends primarily on the nature of the movement, traffic composition, ie the share of a particular type of vehicle in the transport stream.

\section{MATERIALS AND METHODS}

Starting from the global systems that implement the concept of environmental quality monitoring further hardware and softwa we present architecture for an intelligent system to monitor the pollution by the urban sounds and vibrations to provide decision support to reduce pollution. Flow chart of the system of evaluation and monitoring, acoustic pollution presents the stages of data collection, data processing, processes and results (Fig. 1).

To prepare a computer model acoustic model is necessary to know as much detail as the noise level throughout the settlement. Monitoring should be dynamic and continuous (or even regular). In addition, according END (Environmental Noise Directive 2002/49 / EC), the data must be collected separately for periods of the day (07.00-19.00), evening (19.00-23.00) and night (23.00-07.00).

Noise levels can be measured or calculated. The two methods are not mutually exclusive, but complement. The current trend is to produce noise maps using the prediction of noise levels after the introduction of massive input configuration related land, buildings, traffic, environment, etc. The amount of data and their processing requires powerful computing systems.

Measurements are to bring correction model by as many points as significant. Methods can and overlap, such that it can measure the intensity of noise sources in nature, but it can calculate the spatial distribution according to specific standards stipulated by the laws of physics.

Calea Florești street, subject study area, is a section of road with an annual traffic of over 6 million vehicles per year and therefore must 


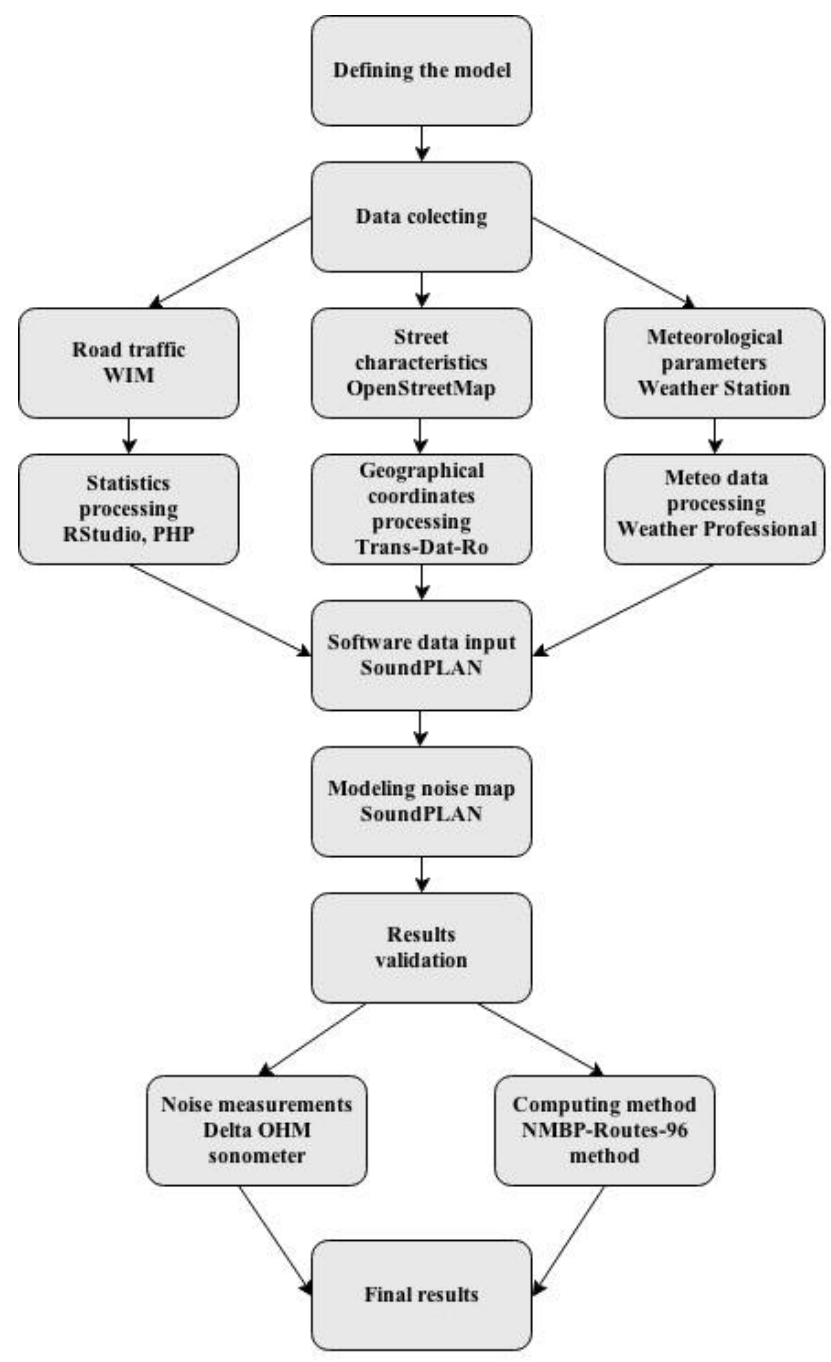

Fig. 1. SUNET System be determined by traffic size gauges automatic precision as HI-TRAC system 100-WIM (Fig. 2).

Traffic count must be adjusted for each of the annual variation of day, evening and night. Most computing applications using noise as an input parameter value hourly traffic as SoundPLAN software and they were further processed data.

Average traffic speeds should be determined for both light vehicles and for heavy ones for all three periods: day, evening and night. They are measured by using the WIM and should be between 20-110 km/h for light vehicles between 20-100 $\mathrm{km} / \mathrm{h}$ for heavy vehicles. Using data collected by WIM technology will cause the average traffic speeds for the two categories of vehicles.

To calculate equivalent noise level of longterm strategic noise mapping should be applied meteorological correction. This correction will depend on the position of the source and receiver, and European legislation recommends using a standard meteorological corrections.

Data entry in SoundPlan software, complementary to traffic intensity, its composition and traffic speed, were other parameters such as traffic flow type, road gradient, road surface type and age.

French standard "XPS 31-133" presents diagrams that provide the noise level Leq (1h) in $\mathrm{dB}(\mathrm{A})$, which is also known as noise emission (E). The noise level is set separately for light vehicle $\left(E_{l v}\right)$ for a heavy vehicle $\left(E_{h v}\right)$ following $E$ is a function of speed, traffic flow and longitudinal profile.

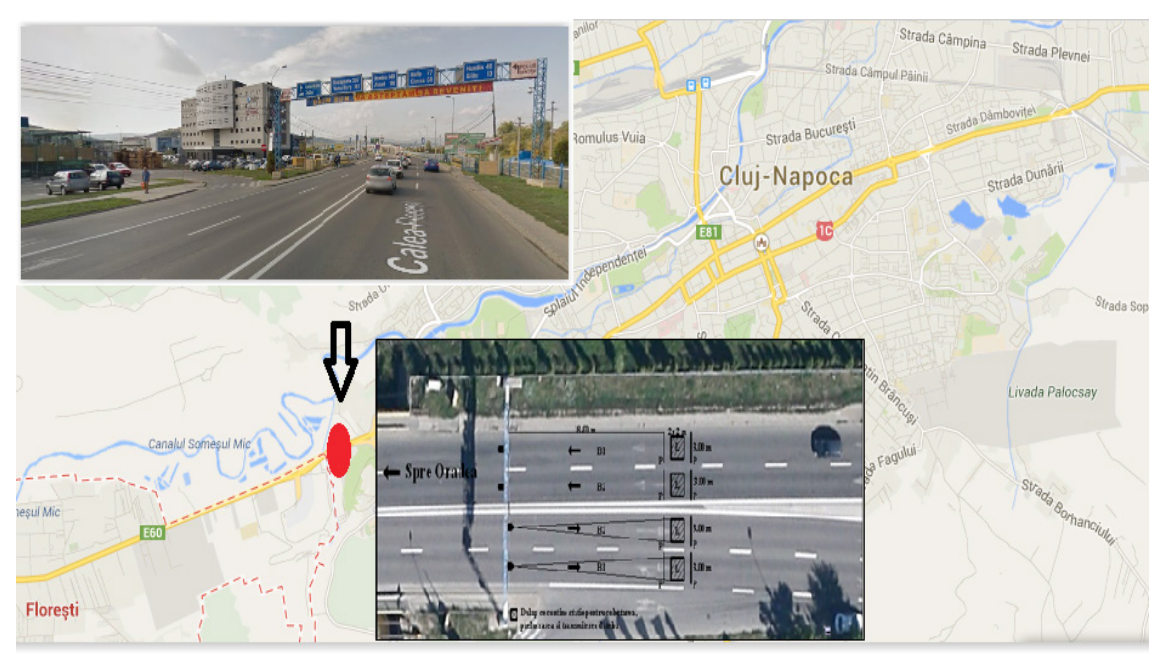

Fig. 2. WIM system location on the E60 road (Calea Floreşti) 


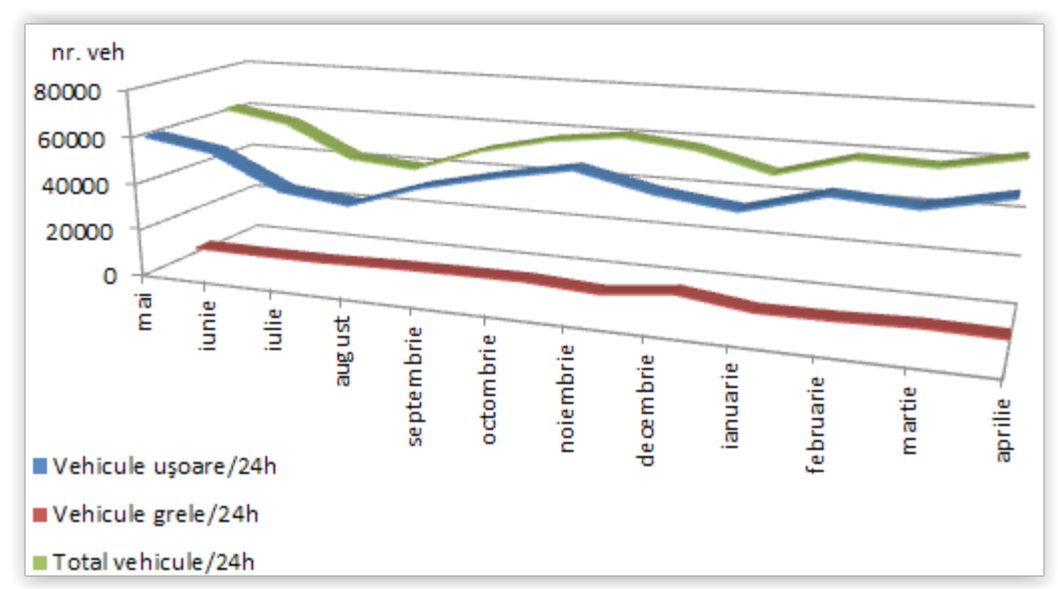

Fig. 2. Monthly daily average intensity variation

Note: Light vehicles, heavy vechicles and total vechicles are represented by different colors:blue, red and respectively green.
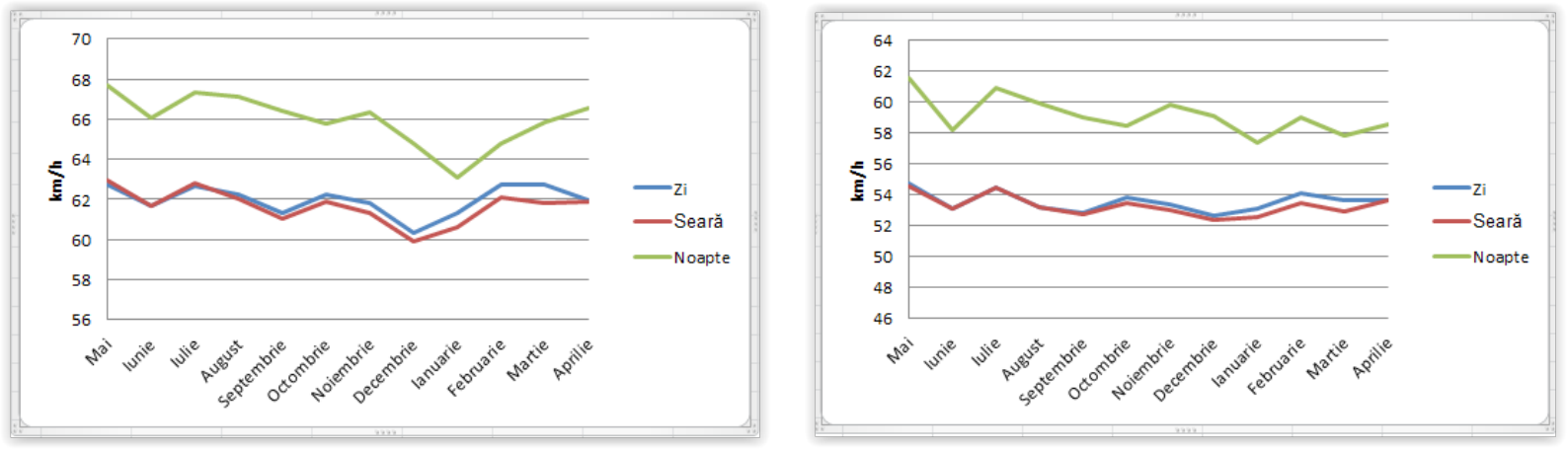

Fig. 3. V50 average traffic speed variation during a year for light and heavy vehicles

Note: Defined time intervals of the day, evening and night are represented by different colors:blue, red and respectively green.

The overall acoustic power meter along the length of the source in $\mathrm{dB}(\mathrm{A}), \mathrm{L}_{\mathrm{AW} / \mathrm{m}}$ is calculated by the following formula traffic-dependent component (E-emisions and Q-traffic flows):

$L_{A W / m}=10 \log \left(10^{\left(E_{l v}+10 \lg Q_{l v}\right) / 10}+\right.$ $\left.+10^{\left(E_{h v}+10 \lg Q_{h v}\right) / 10}\right)+20$

(NMPB-Routes-96, 1995)

Acoustic level at medium and long range environmental assessment long interval is calculated using the mathematical relationship according to SR ISO 1996-2:2008/C91:

$L_{A \in q, L T}=10 * \log \left[\frac{1}{N} \sum_{i=1}^{N} 10^{0,1\left(L_{A \varepsilon q, T}\right)_{i}}\right]$

(ISO, 2009)
Noise prediction models, currently available for noise mapping are semi-empirical methods combining physical sound propagation outdoors with empirical data from repeated experiments. Sound propagates freely. In nature sounds are reflected, absorbed, there are reverberations etc.

Noise contour limit line and noise map scale will be calculated based on all the calculation and will be calculated based on a rectangle that includes all the geometry of the map, if the calculation is defined. Creating noise map is to define surface noise calculation and noise display on the map. Thus, a particular range of intensities is assigned a particular color, a dark outline around the source and the value displayed in the map legend.

SoundPlan software under evaluation for the three periods of time, day, evening, night and evening, additions will automatically appear (5dB) and night $(10 \mathrm{~dB})$ in accordance with European legislation for calculating $\mathrm{L}_{\mathrm{den}}$ : 


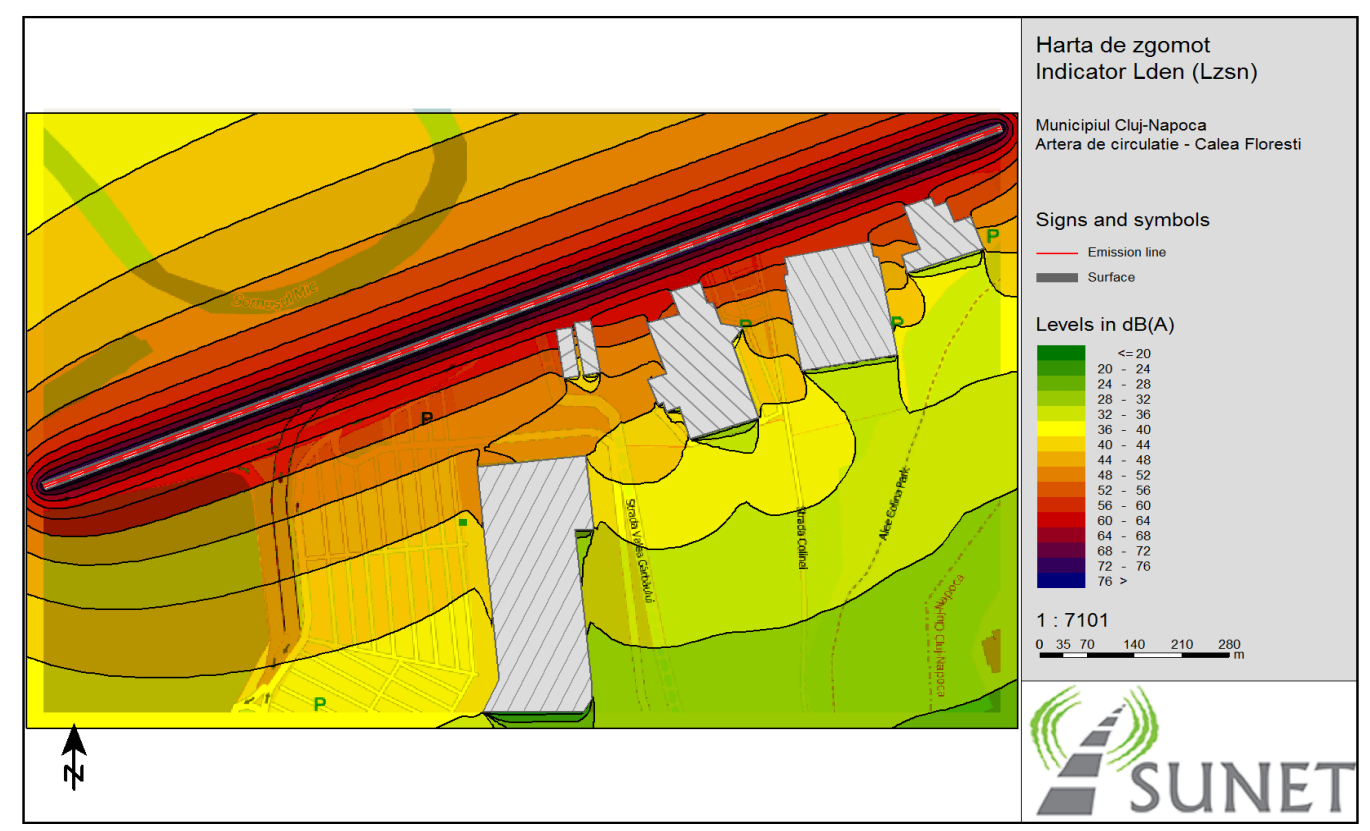

Fig. 3. Noise map for $L_{d e n}$ indicator

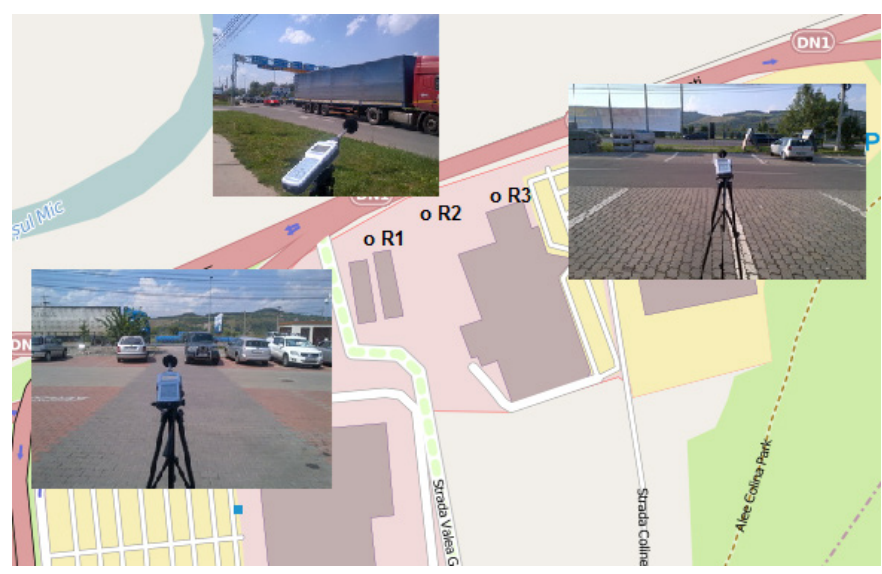

Fig. 4. The measuring points corresponding to the pitch receptors R1, R2 and R3

Tab. 2. Results of measurements for noise indicators

\begin{tabular}{cccc}
\hline Indicator & $\begin{array}{c}\text { Receptor R1 } \\
\mathrm{dB}(\mathrm{A})\end{array}$ & $\begin{array}{c}\text { Receptor R2 } \\
\mathrm{dB}(\mathrm{A})\end{array}$ & $\begin{array}{c}\text { Receptor R3 } \\
\mathrm{dB}(\mathrm{A})\end{array}$ \\
\hline $\mathrm{L}_{\text {day }}$ & 65,49 & 76,79 & 63,64 \\
\hline $\mathrm{L}_{\text {evening }}$ & 69,62 & 83,83 & 68,60 \\
\hline $\mathrm{L}_{\text {night }}$ & 69,79 & 75,26 & 64,29 \\
\hline $\mathrm{L}_{\text {den }}$ & 67,98 & 78,66 & 65,13 \\
\hline
\end{tabular}


Tab. 3. Comparison of noise indicators values

\begin{tabular}{ccccc}
\hline Results & $\begin{array}{c}\text { Lday } \\
\mathrm{dB}(\mathrm{A})\end{array}$ & $\begin{array}{c}\text { Levening } \\
\mathrm{dB}(\mathrm{A})\end{array}$ & $\begin{array}{c}\text { Lnight } \\
\mathrm{dB}(\mathrm{A})\end{array}$ & $\begin{array}{c}\text { Lden } \\
\mathrm{dB}(\mathrm{A})\end{array}$ \\
\hline $\mathrm{R} 1$ - measured & 65,49 & 69,62 & 69,79 & 67,98 \\
\hline $\mathrm{R} 1$ - calculated & 62,50 & 66,90 & 64,20 & 64,10 \\
\hline Differences & $+2,99$ & $+2,72$ & $+5,59$ & $+3,88$ \\
\hline R2 - measured & 76,79 & 83,83 & 75,26 & 78,66 \\
\hline R2 - calculated & 73,40 & 77,80 & 75,10 & $+3,00$ \\
\hline Differences & $+3,39$ & $+6,03$ & $+0,16$ & 65,13 \\
\hline R3 - measured & 63,64 & 68,60 & 64,29 & 64,00 \\
\hline R3 - calculated & 62,40 & 66,80 & 64,10 & $+1,13$ \\
\hline Differences & $+1,24$ & $+0,20$ & $+0,19$ & \\
\hline
\end{tabular}

$$
\begin{aligned}
& L_{\text {den }}=10 \lg \frac{1}{24}\left(12 * 10^{\frac{L_{\text {day }}}{10}}+\right. \\
& \left.+4 * 10^{\frac{L_{\text {evening }}+5}{10}}+8 * 10^{\frac{L_{\text {night }}+10}{10}}\right)
\end{aligned}
$$

(END, 2002).

During the period May 2013 - April 2014 were conducted noise measurements at different days of the week and at different times repeatedly. Measurements were made on the section of road on Calea Floreşti analyzed by using soundlevel meter Delta Ohm. To validate the results of measurements were made in three different measurement points, called receptors (Fig. 4).

\section{RESULTS AND DISCUSSION}

The results of the comparative analysis between noise measurements (measured values) and the values obtained by simulation with software SoundPLAN (calculated values) are presented in table 3 .

It appears that the largest differences between measured and calculated values between 3 and $6 \mathrm{~dB}$ and that in most cases the values are very close. This aspect confirms that the method of calculation was a correct one and that model is a valid one, and the differences may be caused by a number of factors such as:

- type of traffic flow changes at different time intervals;

- the software does not account for all the imperfections of the undercarriage and the actual condition of the road at the time the measurements were made;
- measurements were carried out in intervals of 10,15 or 30 minutes, while the software generates the average rating for 12 hours;

noise measurements include effects of other noise sources, while the software takes into account the strict traffic;

- using a mathematical model of obstacles (buildings) and the source of noise (street) is by definition a simplification of reality;

- weather conditions during the measurements may be different from those we consider software.

\section{CONCLUSION}

A noise map is the summary of a simulation with a set of input data and analytical calculation method, implemented numerically as an algorithm. Inevitably such a product has errors, the causes can be many:

- specific error calculation method: each method using a series of approximations of noise propagation, from simple approximations as limiting the number of reflections, to complex approximations such as the appearance of diffraction phenomena in the model;

- implementation error of the analytical method in numerical form: correct transposition relations account by the programmer, such as type integral calculus relations;

- modeling errors: the inevitable any model created in a software may be a reflection of reality identical, with simplifications related to the form of buildings, building materials of obstacles etc.

These errors can be reduced if there is a constant concern for collecting and storing this information electronically, in a format easily 
accessible calculation of noise maps software. Otherwise, it is imperative to verify the simulation results by measuring the acoustic map.

More accurate characterization of traffic parameters and precise results for noise level are the purposes of the SUNET system, in order to propose appropriate action plans to decrease noise pollution in urban area.

\section{REFERENCES}

1. Manvell D (1999). Managing Urban Noise in Cities - An Integrated Approach to Mapping, Monitoring, Evaluation and Improvement. Proceedings of Internoise.

2. Sandberg U, Ejsmont J (2002). Tyre/Road Noise Reference Book, INFORMEX, Sweden
3. SILENCE (2008). Practitioner Handbook for Local Noise Action Plans.

4. *** Directive 2002/49/EC of the European Parliament and of the Council (2002). Declaration by the Commission in the Conciliation Committee on the Directive relating to the assessment and management of environmental noise, Official Journal L 189, 18/07/2002 P.0012 - 0026.

5. ***H.G. 321/2005 (2005) - Government Decision on the assessment and management of environmental noise ", Official Gazette no. 19/10 I.2008.

6. ***ISO 1996-2:2008/C91:2009 (2009).Acoustics. Description, measurement and assessment of environmental noise. Part 2: Determination of environmental noise levels.

7. ***NMPB-Routes-96 French Method (1995). (SETRA -CERTU - LCPCCSTB) Official Journal of 10 May 1995, Article 6. 